\title{
Comparative mapping combined with homology- based cloning of the rice genome reveals candidate genes for grain zinc and iron concentration in maize
}

\author{
Tiantian Jin, Jingtang Chen, Liying Zhu, Yongfeng Zhao, Jinjie Guo and Yaqun Huang*
}

\begin{abstract}
Background: Grain zinc and iron concentration is a complex trait that is controlled by quantitative trait loci (QTL) and is important for maintaining body health. Despite the substantial effort that has been put into identifying QTL for grain zinc and iron concentration, the integration of independent QTL is useful for understanding the genetic foundation of traits. The number of QTL for grain zinc and iron concentration is relatively low in a single species. Therefore, combined analysis of different genomes may help overcome this challenge.

Results: As a continuation of our work on maize, meta-analysis of QTL for grain zinc and iron concentration in rice was performed to identify meta-QTL (MQTL). Based on MQTL in rice and maize, comparative mapping combined with homology-based cloning was performed to identify candidate genes for grain zinc and iron concentration in maize. In total, $22 \mathrm{MQTL}$ in rice, 4 syntenic MQTL-related regions, and $3 \mathrm{MQTL}$-containing candidate genes in maize (ortho-mMQTL) were detected. Two maize orthologs of rice, GRMZM2G366919 and GRMZM2G178190, were characterized as natural resistance-associated macrophage protein (NRAMP) genes and considered to be candidate genes. Phylogenetic analysis of NRAMP genes among maize, rice, and Arabidopsis thaliana further demonstrated that they are likely responsible for the natural variation of maize grain zinc and iron concentration.

Conclusions: Syntenic MQTL-related regions and ortho-mMQTL are prime areas for future investigation as well as for marker-assisted selection breeding programs. Furthermore, the combined method using the rice genome that was used in this study can shed light on other species and help direct future quantitative trait research. In conclusion, these results help elucidate the molecular mechanism that underlies grain zinc and iron concentration in maize.
\end{abstract}

Keywords: Maize, Grain zinc and iron concentration, Meta-analysis, Comparative mapping, Ortho-mMQTL

\section{Background}

Zinc and iron are essential micronutrients for all living organisms and play important roles in maintaining life. Zinc and iron deficiencies lead to serious diseases such as low immunity, stunted growth, and iron-deficiency anemia [1]. According to the World Health Organization (2002), zinc and iron deficiencies are the top-ranked health risk factors in developing countries [2]. It is estimated that about $30 \%$ and $60 \%$ of the world's population suffers from diseases that are caused by zinc deficiency

\footnotetext{
* Correspondence: hyqun@hebau.edu.cn

Hebei Branch of Chinese National Maize Improvement Center, Agricultural University of Hebei, Baoding, People's Republic of China
}

and iron deficiency, respectively [3-5]. Biofortification is the improvement of the concentration of essential minerals and vitamins in major staple crops through conventional plant breeding and modern biotechnology. This, combined with increasing the daily intake of such crops, has proven to be the most economical and sustainable approach for relieving micronutrient deficiency in the last decade worldwide [6-8].

Understanding the genetic mechanisms behind biofortified traits is the first step in biofortification. Over the past few years, some loci that are responsible for zinc and iron concentration-related traits have been detected through quantitative trait loci (QTL) mapping in various 
kinds of crops, in particular in grains of major staple foods such as rice (Oryza sativa L.) [9-16] and maize (Zea mays L.) [17-20], which have been shown to contain low levels of micronutrients. However, previous results that pertained to the genomic location, confidence intervals or total variance explained by QTL were inconsistent because of different genetic backgrounds, environments, and/or mapping methods. Therefore, comparative analysis of QTL that are revealed by independent experiments has become a popular research topic with substantial challenges.

Instead of manually compiling a large amount of QTL information, meta-analysis has been shown to be an effective tool for integrating and re-analyzing such data [21]. Using this method, the number of "real" QTL that were represented by QTL detected in different studies could be calculated and the refined position and the reduced confidence interval of the "real" QTL could be estimated. Meta-analysis has been used in different species to analyze a wide variety of traits, including grain yield and its related traits, flowering time and photoperiod sensitivity, drought tolerance, disease resistance, cold stress, nitrogen use efficiency, grain moisture, root and leaf architecture traits, fiber quality, oil content, and plant maturity traits [22-39]. We previously performed a meta-analysis on zinc and iron concentration in maize grains, and 10 meta-QTL (MQTL) were found [17]. MQTL could increase the accuracy and pace of genetic improvement of crops.

In the meta-analysis of grain zinc and iron concentration in maize, we found that the number of QTL is far less than those that are related to easily available traits such as plant height, because the phenotypic values of such traits are difficult to quantify. Fortunately, previous studies have shown that there is an extensive synteny between maize and rice genomes [40]. Therefore, combined analysis of the two species is an alternative way to use limited resources. Comparative mapping that uses common genetic markers to reveal synteny among different species is an ideal way to integrate the genetic information of independent genomes [41]. Conserved chromosome regions for important agronomic traits of maize and rice have been reported by comparative mapping of QTL in maize and rice [42,43]. Comparative mapping of MQTL with higher reliability could accurately uncover the conserved synteny for traits of interest. However, to our knowledge, no published study has compared MQTL.

In contrast with other visible traits, such as kernel length and width, only a few studies have been conducted on metabolic mechanisms of zinc or iron in maize, and only two gene families, nicotianamine synthase (NAS) and zinc-regulated transporter (ZRT), ironregulated transporter (IRT)-like protein (ZIP), have been cloned and described [44,45]. Alternatively, the metabolic pathways of zinc and iron, from absorption to accumulation, have been extensively studied in rice, and many genes that are involved have been cloned and characterized, such as OsNAS1-3, OsNAAT, OsDMAS1, and OsTOM1, which participate in mobilization and absorption of cations around the rhizosphere [46-52]. Additionally, OsYSL2, 6, 15, 16, 18; OsIRT1, 2, OsZIP1, 3-5, 7a, 8; OsNRAMP1, 3, 5; OsHAM2, 3, 5, 9; OsMTP1, 8.1; OsFRDL1; OsVIT1, 2; and OsTRO2, 3 are responsible for transportation and accumulation of cations in this species [53-91]. This gene information in rice, which is the model plant for other grasses, could be useful for identifying candidate genes for QTL or MQTL in maize [92].

Therefore, in this study, we combined comparative mapping with homology-based cloning using MQTL for grain zinc and iron concentration in maize (mMQTL) and rice (rMQTL) to predict candidate genes for maize. First, a meta-analysis on published QTL that control grain zinc and iron concentration-related traits in rice was performed to detect MQTL in this species. Then, these were compared with grain zinc and iron concentration MQTL in maize, which was previously reported by us through comparative mapping to identify the conserved synteny. Furthermore, positions of MQTL for maize zinc and iron concentration in grains and maize orthologs of rice zinc and iron metabolism-related genes were compared to reveal the relationship between these genes and the natural variation of this trait. Finally, phylogenetic degeneration of maize orthologs of the rice natural resistance-associated macrophage protein (NRAMP) gene family was elucidated to provide a foundation for further functional characterization.

\section{Results}

QTL meta-analysis for zinc and iron concentration in rice grains

Meta-analysis was conducted to integrate and refine QTL for grain zinc and iron concentrations in rice when 74 of the 90 collected QTL were projected onto the consensus map. According to the definition of metaanalysis, chromosome regions that contained only one QTL were ignored during the analysis, which resulted in 63 QTL that were involved in integration. In total, 22 rMQTL were distributed across all rice chromosomes except chromosomes 10 and 11: three rMQTL on chromosomes 1, 2, 3, 7, and 8; two rMQTL on chromosomes 5 and 6; and one each on chromosomes 4, 9, and 12 (Figure 1).

Detailed information about rMQTL is provided in Table 1 . The 22 rMQTL integrated two to six original QTL that were identified by independent experiments. The confidence intervals of the rMQTL, ranging from $7.68 \mathrm{cM}$ (rMQTL3.3) to $20.66 \mathrm{cM}$ (rMQTL2.2), were 


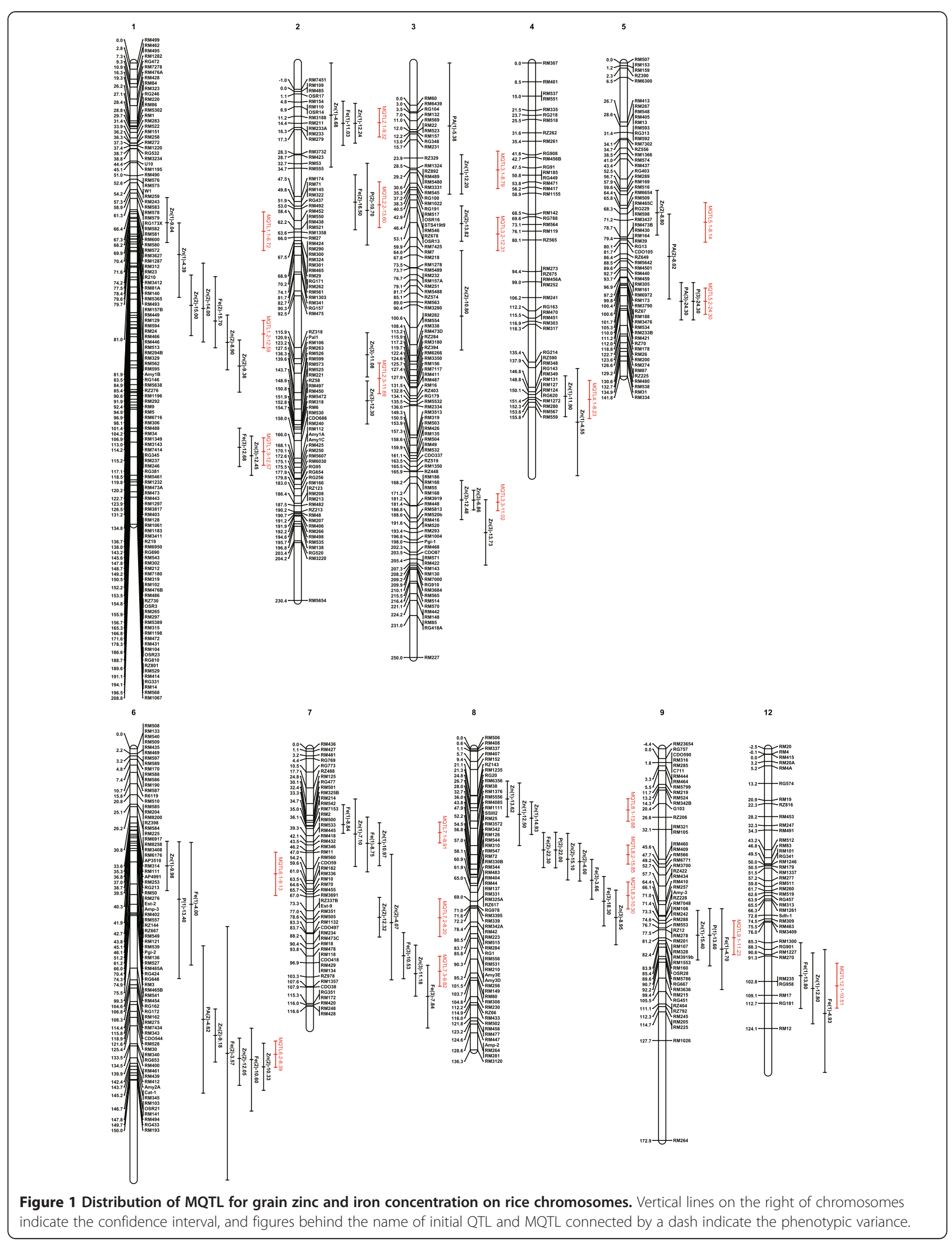


Table 1 MQTL for grain zinc and iron concentration in rice identified by meta-analysis

\begin{tabular}{|c|c|c|c|c|c|c|c|c|c|c|c|c|}
\hline MQTL & Chr. & $\begin{array}{l}\text { Position } \\
\text { (cM) }\end{array}$ & QTL region & $\begin{array}{l}\text { Closest } \\
\text { maker }\end{array}$ & AIC & $\begin{array}{l}\text { QTL } \\
\text { model }\end{array}$ & $\begin{array}{l}\text { No. of } \\
\text { initial QTL }\end{array}$ & $\begin{array}{l}\text { Mean phenotypic } \\
\text { variance of the QTL }\end{array}$ & $\begin{array}{l}\text { Mean initial } \\
\text { QTL CI (cM) }\end{array}$ & $\begin{array}{l}\text { MQTL Cl } \\
(95 \%)(\mathrm{cM})\end{array}$ & $\begin{array}{l}\text { Physical } \\
\text { distance (bp) }\end{array}$ & $\begin{array}{l}\text { Related } \\
\text { trait }\end{array}$ \\
\hline rMQTL1.1 & 1 & 76.17 & RM600-RM5638 & RM3412 & 97.82 & 4 & 2 & 6.72 & 27.08 & 17.47 & $9,464,568-20,936,057$ & $\mathrm{Zn}$ \\
\hline rMQTL1.2 & 1 & 122.71 & RM246-RM403 & RM443 & & & 5 & 12.59 & 28.76 & 12.40 & $27,336,316-29,385,871$ & $\mathrm{Zn}, \mathrm{Fe}$ \\
\hline rMQTL1.3 & 1 & 175.87 & RM1198-RM104 & RM431 & & & 2 & 12.57 & 17.58 & 12.43 & $37,603,776-40,168,103$ & $\mathrm{Zn}, \mathrm{Fe}$ \\
\hline rMQTL2.1 & 2 & 14.12 & RM110-RM3732 & RM211 & 75.33 & 4 & 3 & 9.32 & 28.42 & 12.90 & $1,326,951-4,407,973$ & $\mathrm{Zn}, \mathrm{Fe}$ \\
\hline rMQTL2.2 & 2 & 51.26 & RM555-RM550 & RG437 & & & 2 & 13.60 & 30.95 & 20.66 & $4,305,688-12,464,529$ & $\mathrm{Fe}, \mathrm{P}$ \\
\hline rMQTL2.3 & 2 & 129.86 & Pal1-RM599 & RM263 & & & 2 & 11.69 & 19.69 & 13.92 & $24,973,386-27,115,300$ & $\mathrm{Zn}$ \\
\hline rMQTL3.1 & 3 & 29.33 & RM231-RM1022 & RM489 & 83.49 & 4 & 2 & 8.79 & 38.55 & 16.97 & 2,454,089-7,233,990 & $\mathrm{Zn}, \mathrm{PA}$ \\
\hline rMQTL3.2 & 3 & 58.28 & RM546-RM218 & RM7425 & & & 2 & 12.31 & 30.50 & 15.06 & $6,164,117-8,406,578$ & $\mathrm{Zn}$ \\
\hline rMQTL3.3 & 3 & 179.73 & RM168-RM5813 & RM3919 & & & 3 & 11.02 & 18.73 & 7.68 & $28,098,585-30,981,264$ & $\mathrm{Zn}, \mathrm{Fe}$ \\
\hline rMQTL4.1 & 4 & 152.34 & RM348-RM559 & RM280 & 33.37 & 3 & 2 & 8.23 & 33.55 & 17.33 & $32,835,501-35,336,879$ & $\mathrm{Zn}$ \\
\hline rMQTL5.1 & 5 & 72.11 & RM516-RZ649 & RM3437 & 29.84 & 2 & 2 & 8.41 & 29.33 & 17.91 & $8,304,202-19,608,342$ & $\mathrm{Zn}, \mathrm{PA}$ \\
\hline rMQTL5.2 & 5 & 107.85 & RM3476-RM178 & RM233B & & & 2 & 24.30 & 16.91 & 11.96 & $23,906,571-25,164,524$ & PA \\
\hline rMQTL6.1 & 6 & 56.64 & RM539-RG424 & RM527 & 109.12 & 4 & 3 & 9.13 & 46.55 & 19.61 & $8,170,581-19,814,539$ & $\mathrm{Zn}, \mathrm{Fe}, \mathrm{P}$ \\
\hline rMQTL6.2 & 6 & 138.25 & RM30-RM345 & RM461 & & & 6 & 8.39 & 47.61 & 11.86 & $27,253,297-30,865,997$ & $\mathrm{Zn}, \mathrm{Fe}, \mathrm{PA}$ \\
\hline rMQTL7.1 & 7 & 37.91 & RM501-RM432 & RM533 & 76.23 & 3 & 4 & 8.91 & 21.93 & 9.41 & $8,006,856-18,959,778$ & $\mathrm{Zn}, \mathrm{Fe}$ \\
\hline rMQTL7.2 & 7 & 76.47 & RM3691-RM234 & RM351 & & & 2 & 8.20 & 37.38 & 17.09 & $19,226,136-25,473,814$ & $\mathrm{Zn}$ \\
\hline rMQTL7.3 & 7 & 100.73 & RM478-RM1357 & RZ978 & & & 3 & 9.85 & 24.15 & 13.62 & $25,950,515-28,852,240$ & $\mathrm{Zn}, \mathrm{Fe}$ \\
\hline rMQTL8.1 & 8 & 27.71 & RM1235-RM1376 & RM38 & 95.34 & 4 & 3 & 13.68 & 19.77 & 10.19 & $1,209,754-3,169,069$ & $\mathrm{Zn}$ \\
\hline rMQTL8.2 & 8 & 47.86 & RM4085-RM25 & RM1111 & & & 4 & 15.85 & 17.51 & 8.60 & $4,450,273-4,378,594$ & $Z n, F e, P$ \\
\hline rMQTL8.3 & 8 & 66.44 & RM547-RM339 & RM483 & & & 3 & 10.30 & 21.71 & 12.21 & $5,92,402-17,945,202$ & $\mathrm{Zn}, \mathrm{Fe}$ \\
\hline rMQTL9.1 & 9 & 81.06 & RM242-RM5786 & RM201 & 26.17 & 2 & 3 & 11.23 & 28.33 & 15.39 & $18,811,120-20,482,666$ & $\mathrm{Zn}, \mathrm{Fe}, \mathrm{P}$ \\
\hline rMQTL12.1 & 12 & 104.78 & RM270-RM12 & RG958 & 40.16 & 3 & 3 & 10.51 & 39.17 & 20.32 & $25,002,547-26,988,436$ & $\mathrm{Zn}, \mathrm{Fe}$ \\
\hline
\end{tabular}


narrower than the mean confidence intervals of their respective original QTL. At three rMQTL, rMQTL3.3, rMQTL7.1, and rMQTL8.2, the confidence intervals were less than $10 \mathrm{cM}$. The phenotypic variance of the rMQTL varied from 6.72\% (rMQTL1.1) to $24.30 \%$ (rMQTL5.2), and at 12 of the 22 rMQTL, the phenotypic variance was greater than $10 \%$. In general, the rMQTL were represented by several original QTL that were associated with both grain zinc concentration and grain iron concentration.

\section{Syntenic MQTL-related regions between maize and rice}

Comparative mapping of MQTL for grain zinc and iron concentration between maize and rice was performed to study the conserved synteny for such traits when respective MQTL data were available through metaanalysis. In total, four syntenic MQTL-related regions with more than two common markers were received: mMQTL2.1 on maize chromosome 2 was co-linear with rMQTL7.1 on rice chromosome 7 (Figure 2a), mMQTL3 on maize chromosome 3 was co-linear with rMQTL1.1 and rMQTL1.3 on rice chromosome 1 (Figure 2b), mMQTL5 on maize chromosome 5 was co-linear with rMQTL2.2 on rice chromosome 2 (Figure 2c), and mMQTL9.2 on maize chromosome 9 was co-linear with rMQTL3.1 on rice chromosome 3 (Figure 2d).

Extensive database searching for common markers that were associated with maize and rice MQTL maps was carried out to seek the functional annotation information. An overgo probe, pco110312/AY107242, which is located in the intervals of mMQTL9.2 and rMQTL3.1, was able to anchor on the following metal transport protein-coding genes: GRMZM2G178190 in maize and OsNRAMP2, which belongs to the NRAMP gene family in rice (Figure 2d). Sequence alignment indicated that the protein sequence of the two genes showed very high identity (92\%). Other common markers, however, had no functional information that was related to the target trait we studied.

\section{Characterization of the ortho-mMQTL}

A total of 38 maize orthologs of rice zinc and iron metabolism-related genes were obtained through a homology-based cloning method, and their detailed information is listed in Table 2. After comparing the positions of mMQTL and maize orthologs of wellcharacterized rice genes, three ortho-mMQTLs that contained orthologs were discovered. The genomic region of ortho-mMQTL2.1 possessed the following maize orthologs: GRMZM2G085833 of the rice-cloned gene, OsYSL6, which belongs to the yellow stripe1-like (YSL) gene family; GRMZM2G366919 of the rice-cloned gene, OsNRAMP1, which belongs to the NRAMP gene family; and GRMZM2G175576 of the rice clone-gene,
OsHMA3, which belongs to the heavy metal ATPase (HMA) gene family. The genomic region of orthomMQTL3 possessed the following maize orthologs: GRMZM2G063306 (ZmTOM1) of the rice-cloned gene OsTOM1 and GRMZM2G057413 of the rice-cloned gene OsIRO2, which is a basic helix-loop-helix transcription factor. Additionally, the genomic region of ortho-mMQTL10 that possessed the maize ortholog GRMZM2G026391 of the rice-cloned gene OsYSL16 also belonged to the rice YSL gene family.

In comparison, ortho-mMQTL2.1 has attracted a substantial amount of attention because it is a "hot spot" of maize orthologs of rice genes and also because of the synteny between MMQTL2.1 and rMQTL7.1 that was revealed by comparative mapping. Additionally, the rice gene OSNRAMP1, which is located in the interval of MQTL7.1, is homologous with GRMZM2G366919, which is a maize ortholog that is located in the region of mMQTL2.1. Therefore, MMQTL2.1 and rMQTL7.1 were co-linear and contained a pair of homologous genes, GRMZM2G366919/OsNRAMP1.

\section{Identification and analysis of maize NRAMP genes}

Because of the homology of the two pairs of genes in maize and rice, GRMZM2G366919/OsNRAMP1 and GRMZM2G178190/OsNRAMP2, and their significant association with the natural variance of grain zinc and iron concentration, members of the NRAMP gene family in maize were searched, and a phylogenetic tree was built to elucidate the relationship between the gene function and genome evolution as well as provide a foundation for further functional characterization.

Eight putative genes in the maize genome were identified using reported NRAMP proteins from Arabidopsis thaliana as database queries. The phylogenetic tree was then constructed when all of the maize NRAMP proteins were aligned with the $A$. thaliana and rice NRAMP proteins (Figure 3). The NRAMP genes were divided into two groups based on the phylogenetic relationships: Class I and Class II. Most of the maize (5 of 8) and rice (5 of 7) NRAMP genes were categorized into Class I. A few were categorized into Class II. For A. thaliana, a model eudicot, the opposite occurred. A phylogenetic analysis showed that GRMZM2G366919, which is closely related to OsNRAMP1, was placed into Class I, a class which also contained AtNRAMP1, 6 and OsNRAMP3, 4, 5, 6. GRMZM2G178190, which is closely related to OsN$R A M P 2$, was categorized into Class II, a class which also contained AtNRAMP2, 3, 4, 5 and OsNRAMP2, 7.

\section{Discussion}

Meta-analysis for QTL integration

Grain zinc and iron concentration is a polygenic trait that is controlled by QTL. Quantifying this trait is time 


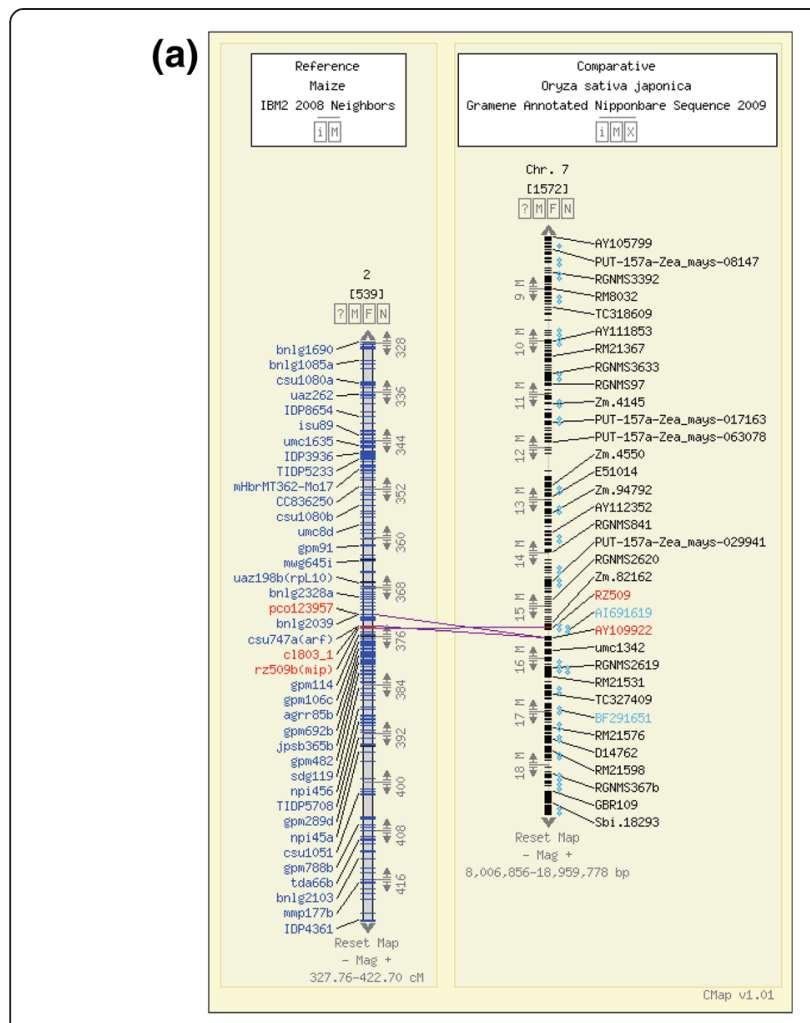

(b)

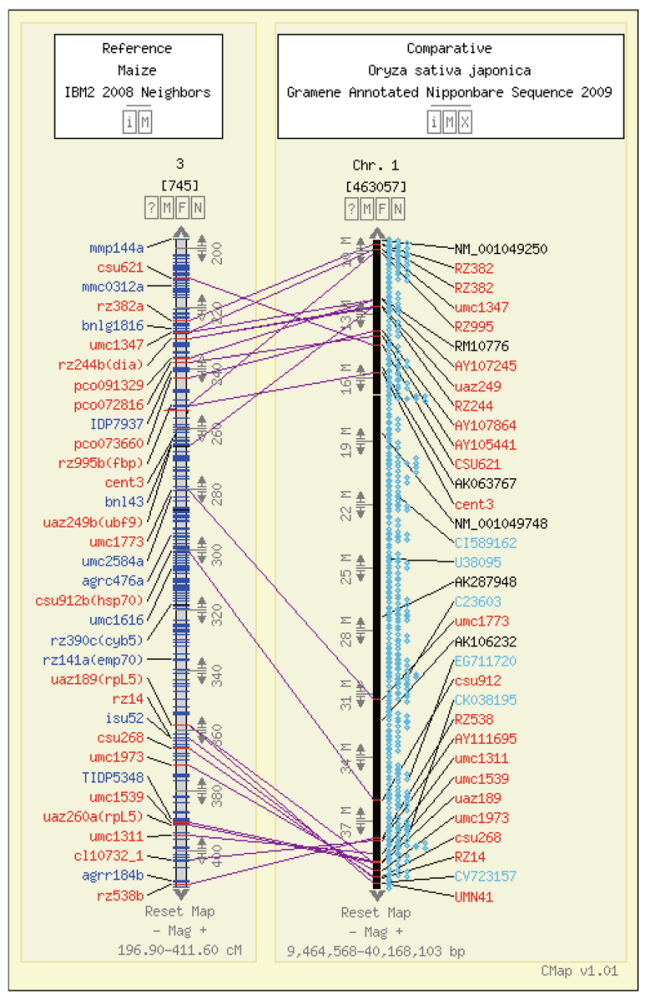

(c)

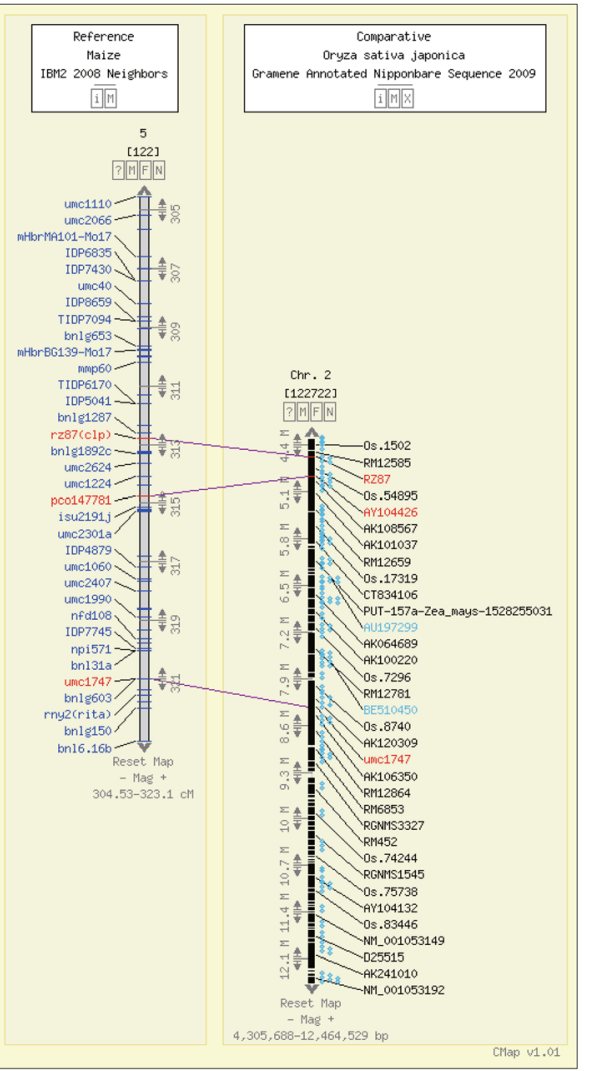

(d)

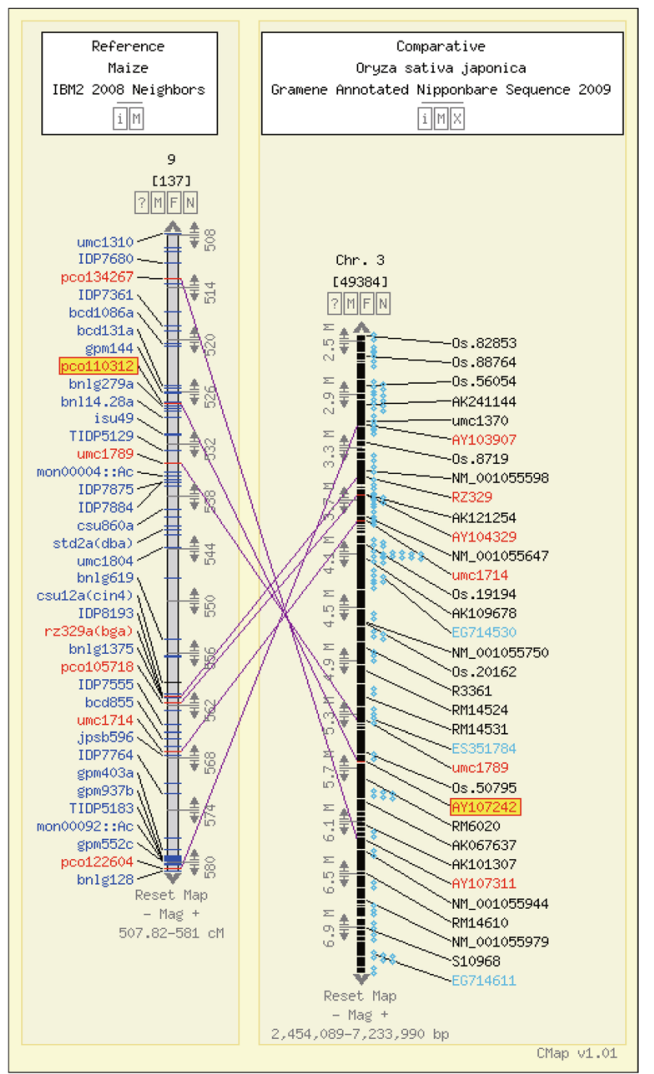

Figure 2 Comparative maps between maize and rice. The confidence interval of mMQTL2.1 was CO-linear with the physical interval of rMQTL7.1 (a); the confidence interval of MMQTL3 was co-linear with the physical intervals of rMQTL1.1 and rMQTL1.3 (b); the confidence interval of mMQTL5 was co-linear with the physical interval of rMQTL2.2 (c); the confidence interval of MMQTL9.2 was co-linear with the physical interval of rMQTL3.1 (d). 
Table 2 Maize orthologs of rice well-characterized genes related to zinc and iron metabolism

\begin{tabular}{|c|c|c|c|c|c|}
\hline References & Rice genes & Accession numbers & Main tissue expression & Gene products & Maize orthologs \\
\hline & & (GenBank/TIGR) & & & (ID/Gene name/mMQTL) \\
\hline [46] & OsNAS1; & AB021746/LOC_Os03g19427; & Leaves $(\mathrm{Zn} / \mathrm{Fe})$, Seeds $(\mathrm{Zn} / \mathrm{Fe})$ & Nicotianamine synthase & GRMZM2G030036/ZmNAS2; \\
\hline \multirow[t]{6}{*}{ [47] } & OsNAS2 & AB023818/LOC_Os03g19420 & $\operatorname{Roots}(\mathrm{Fe})$, Shoots $(\mathrm{Fe})$, & & GRMZM2G034956/ZmNAS1; \\
\hline & & & Leaves(Fe), Seeds(Fe) & & GRMZM2G124785/ZmNAS2;2; \\
\hline & & & & & GRMZM2G312481/ZmNAS1;2; \\
\hline & & & & & GRMZM2G385200/ZmNAS1; \\
\hline & & & & & GRMZM2G704488/ZmNAS6;1; \\
\hline & & & & & AC233955.1_FGT003/ZmNAS6;2 \\
\hline \multirow[t]{2}{*}{ [48] } & OsNAS3 & AB023819/LOC_Os07g48980 & $\operatorname{Roots}(\mathrm{Zn} / \mathrm{Fe})$, Shoots $(\mathrm{Zn} / \mathrm{Fe})$, & Nicotianamine synthase & GRMZM2G050108/ZmNAS5; \\
\hline & & & Seeds(Zn/Fe/Cu) & & GRMZM2G478568/ZmNAS3 \\
\hline [49] & OsNAAT1 & AB206814/LOC_Os02g20360 & $\operatorname{Roots}(\mathrm{Fe} / \mathrm{Zn} / \mathrm{Cd})$, Shoots $(\mathrm{Fe} / \mathrm{Zn} / \mathrm{Cd})$ & Nicotianamine aminotransferase & GRMZM2G096958/ZmNAAT1; \\
\hline [50] & & & Seeds(Fe) & & GRMZM2G412604 \\
\hline [51] & OsDMAS1 & AB269906/LOC_Os03g13390 & Roots(Fe), Shoots(Fe) & Deoxymugineic acid synthase & GRMZM2G060952/ZmDMAS1 \\
\hline [52] & OsTOM1 & AK069533/LOC_Os11g04020 & Roots $(\mathrm{Fe})$, Shoots $(\mathrm{Fe})$, Seeds $(\mathrm{Zn} / \mathrm{Fe} / \mathrm{Cu})$ & DMA efflux transporter & GRMZM2G063306/ZmTOM1/mMQTL3 \\
\hline$[53,54]$ & OsYSL2 & AB126253/LOC_Os02g43370 & $\operatorname{Roots}(\mathrm{Fe}), \operatorname{Shoots}(\mathrm{Fe} / \mathrm{Mn}), \operatorname{Seed}(\mathrm{Fe} / \mathrm{Mn})$ & Iron-phytosiderophore transporter & n.a. \\
\hline [55] & OsYSL6 & AB190916/LOC_Os04g32050 & Leaves(Mn) & Iron-phytosiderophore transporter & GRMZM2G085833/mMQTL2.1 \\
\hline \multirow[t]{2}{*}[56,57]{} & OsYSL15 & AB190923/LOC_Os02g43410 & $\operatorname{Roots}(\mathrm{Fe})$, Shoots $(\mathrm{Fe})$, & Iron-phytosiderophore transporter & GRMZM2G156599/ZmYS1 \\
\hline & & & Leaves(Fe), Seed(Fe) & & \\
\hline$[58,59]$ & OSYSL16 & AB190924/LOC_Os04g45900 & Shoots(Fe), Leaves $(\mathrm{Fe})$ & Iron-phytosiderophore transporter & GRMZM2G026391/mMQTL10 \\
\hline [60] & OsYSL18 & AB190926/LOC_Os01g61390 & Roots(Fe), Leaves(Fe), Flower(Fe) & Iron-phytosiderophore transporter & GRMZM2G004440 \\
\hline$[61,62]$ & OsIRT1 & AB070226/LOC_Os03g46470 & $\begin{array}{l}\text { Roots }(Z n / F e), \text { Shoots }(Z n / F e), \\
\text { Seeds }(Z n / F e)\end{array}$ & Metal ion transporter & GRMZM2G118821/Zm/RT1 \\
\hline [63] & OSIRT2 & AB126086/LOC_Os03g46454 & $\operatorname{Root}(\mathrm{Fe})$ & Metal ion transporter & n.a. \\
\hline [64] & OsZIP1 & AY302058/LOC_Os01g74110 & $\operatorname{Root}(Z n)$ & Zinc/iron transporter & n.a. \\
\hline [64] & OsZIP3 & AY323915/LOC_Os04g52310 & Roots(Zn), Leaves(Zn) & Zinc/iron transporter & GRMZM2G045849/ZmZIP3 \\
\hline$[65,66]$ & OsZIP4 & AB126089/LOC_Os08g10630 & Roots(Zn), Shoots(Zn), Seeds(Zn) & Zinc/iron transporter & GRMZM2G111300/ZmZIP4 \\
\hline \multirow[t]{2}{*}{ [67] } & OsZIP5 & AB126087/LOC_Os05g39560 & $\operatorname{Roots}(Z n), \operatorname{Shoots}(Z n)$ & Zinc/iron transporter & GRMZM2G047762 \\
\hline & & & Leaves(Zn), Seeds(Zn) & & \\
\hline [68] & OsZIP7a & AY275180/LOC_Os05g10940 & $\operatorname{Root}(\mathrm{Fe})$ & Zinc/iron transporter & GRMZM2G015955/ZmZIP7 \\
\hline$[68,69]$ & OsZIP8 & AY327038/LOC_Os07g12890 & Roots(Zn), Shoots(Zn), Seeds(Zn) & Zinc/iron transporter & GRMZM2G093276/ZmZIP8 \\
\hline$[70,71]$ & OsNRAMP1/rMQTL7.1 & AK103557/LOC_Os07g15460 & $\operatorname{Roots}(\mathrm{Cd} / \mathrm{Al})$, Leaves $(\mathrm{Fe} / \mathrm{Cd})$ & Natural resistance associated & GRMZM2G366919/mMQTL2.1 \\
\hline
\end{tabular}

Natural resistance associated macrophage protein

GRMZM2G069198 
Table 2 Maize orthologs of rice well-characterized genes related to zinc and iron metabolism (Continued)

\begin{tabular}{|c|c|c|c|c|c|}
\hline$[73,74]$ & OsNRAMP5 & AK070788/LOC_Os07g15370 & $\begin{array}{l}\text { Roots }(\mathrm{Fe} / \mathrm{Mn} / \mathrm{Cd}), \text { Shoots }(\mathrm{Fe} / \mathrm{Mn} / \mathrm{Cd}) \\
\text { Seeds }(\mathrm{Mn} / \mathrm{Cd})\end{array}$ & $\begin{array}{l}\text { Natural resistance associated } \\
\text { macrophage protein }\end{array}$ & GRMZM2G147560 \\
\hline [75-77] & OsHMA2 & AK107235/LOC_Os06g48720 & $\begin{array}{l}\text { Roots }(Z n), \text { Shoots }(Z n / C d) \\
\text { Leaves }(Z n / C d) \text {, Seeds }(Z n / C d)\end{array}$ & $P_{1 B}$-type heavy-metal ATPases & GRMZM2G099191 \\
\hline$[78,79]$ & OsHMA3 & AB557931/LOC_Os07g12900 & $\operatorname{Roots}(\mathrm{Cd}), \operatorname{Shoot}(\mathrm{Cd}), \operatorname{Seeds}(\mathrm{Cd})$ & $\mathrm{P}_{1 \mathrm{~B}}$-type heavy-metal ATPases & GRMZM2G175576/mMQTL2.1 \\
\hline \multirow[t]{2}{*}{ [80] } & OsHMA5 & AK063759/LOC_Os04g46940 & Roots(Cu),Shoots(Cu), Seeds(Cu) & $\mathrm{P}_{1 \mathrm{~B}}$-type heavy-metal ATPases & GRMZM2G143512 \\
\hline & & & & & GRMZM2G144083 \\
\hline [81] & OsHMA9 & AK241795/LOC_Os06g45500 & $\operatorname{Roots}(\mathrm{Pb}), \operatorname{Shoots}(\mathrm{Zn} / \mathrm{Cu} / \mathrm{Cd} / \mathrm{Pb})$ & $P_{1 B}$-type heavy-metal ATPases & GRMZM2G010152 \\
\hline$[82,83]$ & OSMTP1 & AK100735/LOC_Os05g03780 & $\begin{array}{l}\text { Roots }(Z n / C d / N i), \text { Leaves }(Z n / C d) \\
\text { Seeds }(Z n / C d)\end{array}$ & Cation diffusion facilitator & GRMZM2G477741 \\
\hline [84] & OsMTP8.1 & AK065961/LOC_Os03g12530 & $\operatorname{Roots}(M n)$, Shoot(Mn) & Cation diffusion facilitator & GRMZM2G118497 \\
\hline [85] & OsFRDL1 & AK101556/LOC_Os03g11734 & Roots(Fe), Shoots(Fe) & MATE efflux family protein & GRMZM2G163154 \\
\hline [86] & OsVIT1 & AK059730/LOC_Os04g38940 & Leaves(Zn/Fe), Seeds(Zn/Fe) & Vacuolar membrane transporters & GRMZM2G107306 \\
\hline$[86,87]$ & OsVIT2 & AK071589/LOC_Os09g23300 & $\begin{array}{l}\text { Shoots }(\mathrm{Zn} / \mathrm{Fe} / \mathrm{Cu} / \mathrm{Mn}), \text { Leaves(Zn/Fe), } \\
\text { Seeds(Zn/Fe) }\end{array}$ & Vacuolar membrane transporters & GRMZM2G074672 \\
\hline [88-90] & OsIRO2 & AK073385/LOC_Os01g72370 & $\begin{array}{l}\text { Roots(Fe), Shoots(Fe/Mn), } \\
\text { Leaves(Fe), Seeds(Fe/Mn) }\end{array}$ & bHLH transcription factor & GRMZM2G057413/mMQTL3 \\
\hline [91] & OsIRO3 & AK061515/LOC_Os03g26210 & Roots(Fe), Shoots(Fe) & bHLH transcription factor & GRMZM2G350312 \\
\hline
\end{tabular}




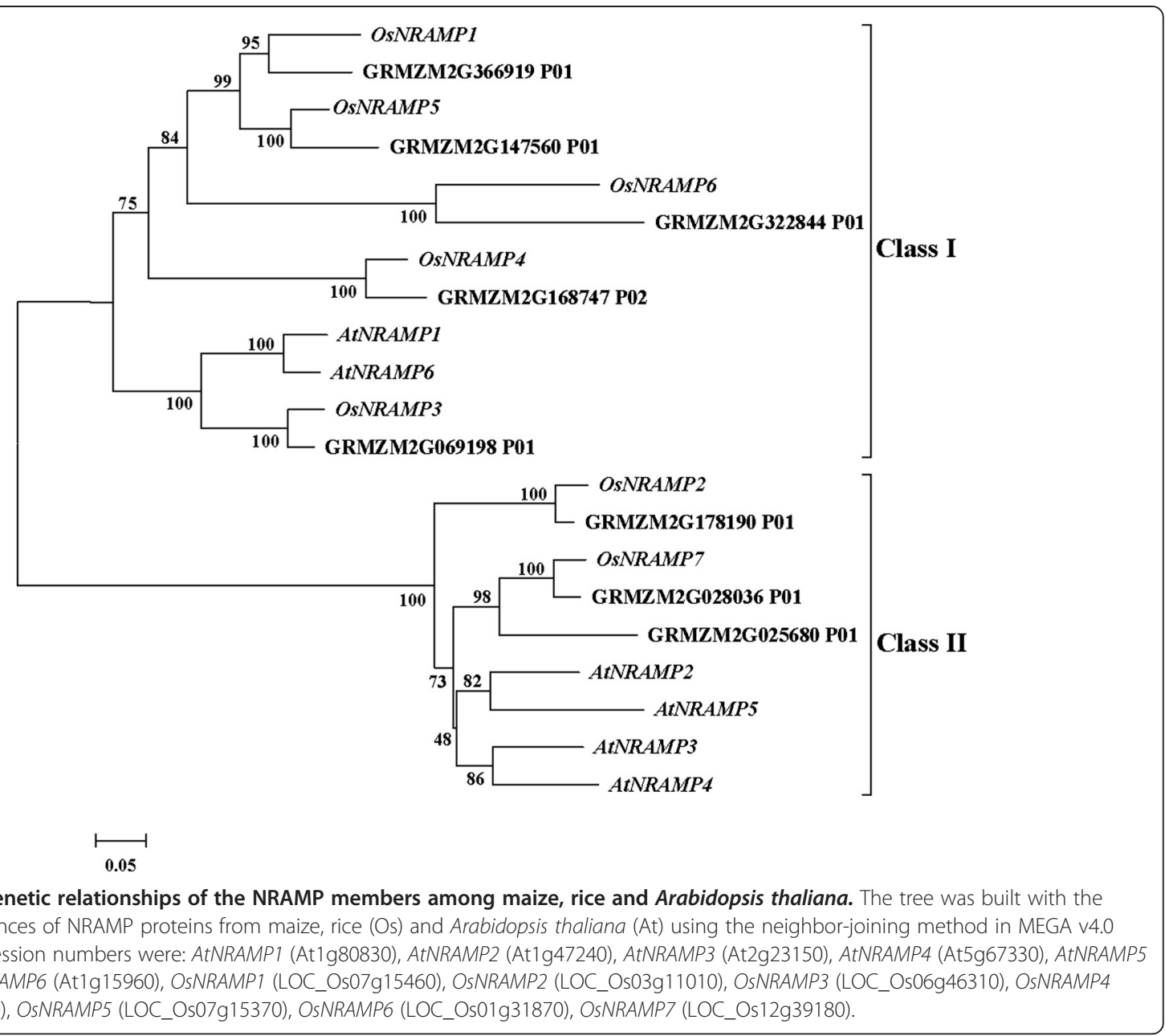

consuming, laborious, and expensive. Consequently, comparing QTL for traits that are identified by independent experiments is important. Meta-analysis has been shown to be effective for QTL integration, and consensus QTL, with more accurate positions and reduced confidence intervals, could be provided [23]. In this study, a total of 90 collected QTL for zinc and iron concentration in rice grains were integrated into 22 rMQTL with a 65\% decrease in total QTL through meta-analysis. The confidence intervals of rMQTL decreased by $29 \%$ to $75 \%$ compared with corresponding mean confidence intervals of several initial QTL.

We have previously conducted a meta-analysis on this trait in maize. Similarly, the $64 \%$ decrease in total QTL and $29 \%$ to $83 \%$ decreases in confidence intervals of mMQTL were achieved [19]. The genetic and physical intervals of MQTL could even be reduced to approximately $2 \mathrm{cM}$ and $500 \mathrm{~kb}$, respectively, in the meta-analysis for grain yield QTL that were detected in grasses during agricultural drought [25]. Therefore, meta-analysis can effectively synthesize and refine multiple independent QTL that are detected under different genetic backgrounds, population types and sizes, mapping statistics, and even phenotypic methodologies. The precise position and reduced confidence intervals for MQTL will pave the way for further QTL fine mapping and map-based cloning.

In addition to integrating independent QTL, metaanalyses can also reveal the genetic correlations among different traits. In a meta-analysis of QTL for leaf architecture traits, four MQTL were identified for three or four traits [38]. In accordance with previous knowledge that plant digestibility is associated with cell wall composition in maize, meta-analysis of QTL for the two traits showed that $42 \%$ of MQTL for digestibility had confidence intervals that overlapped with MQTL for cell wall composition traits [93].

In the current study, most rMQTL for grain zinc and iron concentration in rice were found to include QTL of both traits. Furthermore, in maize, meta-analysis of QTL for the same traits also showed that 8 of $10 \mathrm{mMQTL}$ involved the two QTL traits, simultaneously. The correlation of grain zinc concentration and grain iron concentration at the molecular level strongly indicates that the variation loci responsible for the two traits 
were co-localized in both maize and rice genomes, or even in other species. MQTL for multiple traits could facilitate the genetic improvement through markerassisted selection breeding programs.

\section{Synteny of grain zinc and iron concentration between maize and rice}

There is a well-known evolutionary relationship between maize and rice, which are two major Gramineae species. Comparative mapping of QTL is useful for revealing the syntenic relationships of target traits among different species. For example, comparative analysis revealed that QTL for important agronomic traits, including plant height, number of rows, and kernels per row, are extensively conserved in the syntenic genomic regions of maize and rice $[44,45]$. In this study, comparative mapping for MQTL that control grain zinc and iron concentration in maize and rice was performed, and four syntenic MQTL-related regions were found. Moreover, the pco110312 overgo probe linked mMQTL9.2 and rMQTL3.1, which are syntenic MQTL-related regions, can anchor onto metal transport protein-coding genes, GRMZM2G178190 and OsNRAMP2. Although no candidate gene was found in other syntenic MQTL-related regions, they provided a foundation for future candidate gene mining. Therefore, the results here illustrate that grain zinc and iron concentration are syntenic between maize and rice, and the syntenic MQTL-related regions are reliable for subsequent analysis.

Based on the comparative mapping results, the four syntenic MQTL-related regions discussed aboved all had relatively broad intervals, which indicating that it was easier to find the respective syntenic region in the other species when MQTL had large confidence intervals. These results could provide a foundation for future research on these MQTL. Because of the narrowed intervals, no syntenic regions were found in MQTL with small confidence intervals. However, some of those MQTL, such as mMQTL2.2 and rMQTL8.2, integrated multiple initial QTL and explained a large percent of phenotypic variation, could provide insight into detection of new functional genes that underlie grain zinc and iron concentration.

\section{Homology-based cloning of maize grain zinc and iron concentration-related genes}

Only one candidate gene for grain zinc and iron concentration in maize was discovered in the four conserved genomic regions. Only one gene may have been discovered because the online comparison is limited by the data that are available in public databases. Nevertheless, some rice functionally-characterized zinc and iron metabolism-related genes can be used for homologybased cloning of maize genes. Therefore, the positions of
mMQTL and maize orthologs of rice-cloned genes were compared to validate the function of those genes for grain zinc and iron concentration variation in maize. Three ortho-mMQTLs with candidate genes were found. In particular, ortho-mMQTL2.1, which contained GRMZM2G366919, was co-linear with rMQTL7.1, and the corresponding orthologous gene, OSNRAMP1, was located in the genomic region of rMQTL7.1.

In a similar comparison of locations between maize orthologs of rice yield genes and MQTL, three candidate loci for maize yield were successfully predicted [94]. By mapping maize orthologs of rice- and A. thaliana-cloned genes that are associated with leaf architecture traits on the consensus map before OTL meta-analysis, Ku et al. also discovered candidate genes for the traits that they studied [38]. Overall, functionally-characterized genes in rice, which is a model species of Gramineae, could be used to identify and analyze candidate genes in maize or other grasses.

\section{Characterization of the maize NRAMP gene family}

NRAMP was first identified in rat macrophages as a resistance gene to intracellular pathogens that transport iron [95]. Subsequently, many homologues of rat NRAMP that transport various cations, not merely iron, were characterized in plants. NRAMP genes are, in general, associated with membrane-spanning proteins [96] and widely distributed both in graminaceous and non-graminaceous species. To date, a total of 6 and at least 7 NRAMP genes have been cloned and some of them have been wellcharacterized in A. thaliana and rice, respectively.

In this study, two candidate genes in maize, GRMZM2G366919 and GRMZM2G178190, were identified as being associated with the natural variation of grain zinc and iron concentration through comparative mapping of MQTL combined with a homology-based cloning method with the rice genome. Based on their homology with rice NRAMP genes, members of the maize NRAMP gene family were mined, and a phylogenetic analysis of NRAMP genes in A. thaliana, rice, and maize was carried out to determine the evolutionary relationships among the genes. GRMZM2G366919, which is included in Class I, is closely related to OSNRAMP1, which participates in the control of iron, cadmium, and aluminum homoeostasis in rice $[72,73,97]$. OsNRAMP5, similar to OsNRAMP1, is relatively closely related to GRMZM2G366919, which contributes to iron, cadmium, and manganese transport in rice $[75,76,98]$. Interestingly, AtNRAMP1, which is also contained in Class $\mathrm{I}$, is an iron transporter in $A$. thaliana and is able to rescue both low and high ironsensitive phenotypes of the yeast mutant fet3fet4 [97]. GRMZM2G178190 and OsNRAMP2 are classified into Class II and are most closely related to each other, and 
OSNRAMP2 was predicted to be a metal homeostasis gene in rice, although its specific function has not yet been clarified $[99,100]$. It is also worth noting that, with in Class II, AtNRAMP3 and AtNRAMP4 are capable of transporting iron, cadmium, and manganese in $A$. thaliana [101,102], and AtNRAMP3 disruption can increase the accumulation of zinc in roots under iron starvation [103]. Therefore, the phylogenetic analysis demonstrated that GRMZM2G366919 and GRMZM2G178190 might be responsible for zinc and iron metabolism in maize and might be more likely to regulate their accumulation in grains.

\section{Implications for quantitative trait genetic research}

Zinc and iron concentration in grains is undoubtedly a complex agronomic trait and plays a vital role in maintaining human health. However, the genetic basis of grain zinc and iron concentration remains obscure, despite many studies that have been conducted to identify QTL or genes that underlie this trait. We performed meta-analysis of QTL for grain zinc and iron concentration in rice in the present study and maize in a previous study [17] to detect the respective MQTL. However, in this study, to eliminate the limitation imposed by the lack of genetic information from one genome, we combined comparative mapping and homology-based cloning with the rice genome.

The MQTL allowed mining of candidate genes for grain zinc and iron concentration in maize. Two maize orthologs of rice NRAMP genes validated the power and effectiveness of the combined method that we adopted. Additionally, the combined method, as well as the wellstudied rice genome employed here, can be extended to research on other species or complex traits.

\section{Conclusion}

Enriching the concentration of zinc and iron in edible parts of major crops is an effective way to relieve malnutrition that is caused by zinc and iron deficiencies, and determining the molecular basis of grain zinc and iron concentration is a prerequisite for biofortification. Metaanalysis of QTL for very complicated traits such as grain zinc and iron concentration is important and useful. MQTL that are the integration of multiple independent QTL, with more precise locations and reduced confidence intervals, are useful for facilitating subsequent research. Candidate genes that were retrieved from the combination of comparative mapping of MQTL and homology-based cloning techniques could be used to reveal the molecular mechanisms that underlie zinc and iron concentration in maize grains. Syntenic MQTLrelated regions and ortho-mMQTLs that contain candidate genes could be used for further fine mapping and map-based cloning.

\section{Methods}

\section{QTL meta-analysis}

Three steps were required for conducting the metaanalysis to identify MQTL. First, a bibliographic review on the mapping of QTL for zinc and iron concentrationrelated traits in rice grains was performed. The QTL information was collected from published reports including journal articles and dissertations. In all, eight reports involving nine mapping populations and 90 QTL were compiled. The details of those studies are provided in Table 3. Second, a consensus map that was integrated from multiple independent genetic linkage maps was built. The rice genetic linkage map Cornell SSR 2001 was selected as a reference map on which the maps of 8

Table 3 Bibliography of QTL research for grain zinc and iron concentration in rice used in this study

\begin{tabular}{|c|c|c|c|c|c|c|c|}
\hline $\begin{array}{l}\text { QTL } \\
\text { studies }\end{array}$ & Parents & $\begin{array}{l}\text { Population } \\
\text { types }\end{array}$ & $\begin{array}{l}\text { Population } \\
\text { size }\end{array}$ & $\begin{array}{l}\text { No. of } \\
\text { environments }\end{array}$ & Software and methods & $\begin{array}{l}\text { No. of } \\
\text { QTLs }\end{array}$ & $\begin{array}{l}\text { Related } \\
\text { traits }\end{array}$ \\
\hline [9] & IR64/Azucena & $\mathrm{DH}$ & 129 & 1 & $\begin{array}{l}\text { QTL Cartographer v2.5 Composite } \\
\text { interval mapping }\end{array}$ & 8 & $\mathrm{Zn}, \mathrm{Fe}, \mathrm{PA}$ \\
\hline [10] & LPA/Zhonghua 11 & $\mathrm{~F}_{2}$ & 172 & 1 & R/qtlbim Bayesian model selection & 3 & PA \\
\hline [11] & Fengxinhongmi/Minghui 100 & $\mathrm{~F}_{2}$ & 145 & 1 & $\begin{array}{l}\text { QTL Cartographer v2.5 Composite } \\
\text { interval mapping }\end{array}$ & 3 & $\mathrm{Zn}$ \\
\hline [12] & Chunjiang 06/TN1 & $\mathrm{DH}$ & 120 & 2 & Mapmaker/QTL v1.1 Interval Mapping & 14 & $\mathrm{Zn}, \mathrm{Fe}, \mathrm{P}$ \\
\hline [13] & Hongxiang 1/Song 98-131 & $F_{2: 3}$ & 140 & 1 & $\begin{array}{l}\text { QTL IciMapping v3. } 1 \text { Inclusive } \\
\text { Composite Interval Mapping }\end{array}$ & 6 & $\mathrm{Zn}, \mathrm{Fe}$ \\
\hline [14] & Longjin 1/Xiangruanmi 1578 & $F_{2: 3}$ & 196 & 1 & $\begin{array}{l}\text { QTLCartographer v2.0 Composite } \\
\text { Interval Mapping }\end{array}$ & 14 & $\mathrm{Zn}, \mathrm{Fe}, \mathrm{P}$ \\
\hline [15] & Chuanxiang 29B/ Lemont & RIL & 184 & 2 & $\begin{array}{l}\text { QTL Cartographer v2.5 Composite } \\
\text { Interval Mapping }\end{array}$ & 8 & $\mathrm{Zn}, \mathrm{Fe}$ \\
\hline \multirow[t]{2}{*}{ [16] } & Zhongguangxiang 1/IR75862 & $\mathrm{BC}_{1} \mathrm{~F}_{7}$ & 240 & 2 & QTLMapper v1.0 & 14 & $\mathrm{Zn}, \mathrm{Fe}$ \\
\hline & Ce $258 /$ IR75862 & $\mathrm{BC}_{1} \mathrm{~F}_{7}$ & 240 & 2 & Composite Interval Mapping & 20 & $\mathrm{Zn}, \mathrm{Fe}$ \\
\hline
\end{tabular}


studies were projected to develop the consensus map [104]. Third, a meta-analysis of QTL clusters on each chromosome was launched to detect MQTL. The modified Akaike's information criterion (AIC) was used to select the QTL model; the model with the lowest AIC value was chosen as the best model, indicating the most likely number of "real" QTL on each chromosome [21]. Biomercator v2.1 was used to construct the consensus map with the "map projection" function and to conduct meta-analysis with the "meta-analysis" function [105].

\section{MQTL comparative mapping}

Integrated MQTL for grain zinc and iron concentrationrelated traits in rice were compared with MQTL for the same traits in maize. The CMap program on the Gramene (http://www.gramene.org/) was used to investigate the synteny of grain zinc and iron concentration in the two species. Maize was selected as the reference species using IBM2 2008 Neighbors as the reference map and then the rice physical map, Gramene Annotated Nipponbare Sequence 2009, was added as a comparative map with rMQTL anchored first. In this study, comparative maps with fewer than three common markers were discarded. To facilitate the description, MQTL for grain zinc and iron concentration in maize, which we have previously reported [17], were renamed (Table 4). Common markers that linked the two genomes were searched for (primarily in GeneBank, http:// www.ncbi.nlm.nih.gov/genbank/, and Gramene) to identify their genomic annotation information.

\section{Ortho-mMQTL mining}

Detailed information on 33 cloned rice zinc or iron metabolism-related genes, including NAS, NAAT1, DMAS1, TOM1, YSL, ZIP, NRAMP, HMA, MTP, FRDL, VIT, and IRO was retrieved from the Rice Genome Annotation Project database (http://rice.plantbiology.msu. edu/). Maize orthologs of the 33 rice genes were identified by searching the databases of the Rice Genome Annotation Project, NCBI (http://www.ncbi.nlm.nih.gov/), B73 maize sequence (http://www.maizesequence.org) and Phytozome (http://phytozome.jgi.doe.gov/pz/portal.html) using the BLAST program. Their physical locations were identified using the maize genome browser, MaizeGDB (http://www.maizegdb.org/). Subsequently, the positions of MMQTL and maize orthologs were specifically compared to reveal the relationship between maize orthologs of rice zinc or iron-metabolism related genes and the natural variance of zinc and iron concentration in maize grains. In this study, mMQTL-possessing maize orthologs of rice zinc or iron metabolism-related genes were temporarily called ortho-mMQTL.

Maize NRAMP genes identification and phylogenetic analysis Members of the maize NRAMP gene family were identified using the BLASTP program in the Phytozome database by employing the protein sequence of previously identified $A$. thaliana NRAMP genes as queries. The threshold of e-value and identity for the BLASTP program were set at $1 \mathrm{e}-80$ and $>75 \%$, respectively. In addition, protein motifs were searched for in the Pfam database (http://pfam.sanger.ac.uk) to confirm the candidate sequence that encodes NRAMP proteins. Multiple alignments of NRAMP proteins from maize, rice and $A$. thaliana were performed using the ClustalX program [106]. The phylogenetic tree was constructed using MEGA v4.0 software with the neighbor-joining (NJ) method and 1,000 bootstrap replicates [107].

\section{Supporting data}

The phylogenetic tree of the present study is deposited in Treebase (http://purl.org/phylo/treebase/phylows/study/ TB2:S17020 x -access - code $=113$ cee34da6e7a2427055be 64800c677\&format $=$ html).

Table 4 Renamed maize MQTL with syntenic MQTL in rice

\begin{tabular}{|c|c|c|c|c|c|c|c|}
\hline $\begin{array}{l}\text { Renamed maize } \\
\text { MQTL }\end{array}$ & $\begin{array}{l}\text { Original maize } \\
\text { MQTL }\end{array}$ & Maize bin & Position (cM) & $\begin{array}{l}\text { Confidence } \\
\text { interval (cM) }\end{array}$ & $\begin{array}{l}\text { Physical } \\
\text { distance (bp) }\end{array}$ & $\begin{array}{l}\text { Rice syntenic } \\
\text { MQTL }\end{array}$ & Rice chr. \\
\hline mMQTL2.1 & MQTL1 & $2.04-2.07$ & 377.1 & $327.8-422.7$ & $55,353,009-193,786,994$ & MQTL7.1 & 7 \\
\hline mMQTL2.2 & MQTL2 & 2.07 & 466.7 & $466.7-474.8$ & $202,340,532-204,180,634$ & n.a. & n.a. \\
\hline mMQTL2.3 & MQTL3 & 2.08 & 573.9 & $557.3-589.1$ & $214,654,418-220,845,300$ & n.a. & n.a. \\
\hline mMQTL3 & MQTL4 & $3.04-3.06$ & 305.8 & 196.9-411.6 & $29,978,219-174,835,520$ & MQTL1.1, MQTL1.3 & 1 \\
\hline mMQTL4.1 & MQTL5 & 4.06 & 354.1 & $349.6-367.3$ & $153,770,346-163,275,597$ & n.a. & n.a. \\
\hline mMQTL4.2 & MQTL6 & 4.08 & 462.5 & $447.0-481.2$ & $180,430,966-186,492,818$ & n.a. & n.a. \\
\hline mMQTL5 & MQTL7 & 5.04 & 312.8 & $304.5-323.1$ & $84,815,350-150,635,401$ & MQTL2.2 & 2 \\
\hline mMQTL9.1 & MQTL8 & 9.01 & 68.5 & $62.3-82.3$ & $9,117,641-11,575,112$ & n.a. & n.a. \\
\hline mMQTL9.2 & MQTL9 & $9.06-9.07$ & 554.4 & $507.8-581.0$ & $146,944,409-151,490,783$ & MQTL3.1 & 3 \\
\hline mMQTL10 & MQTL10 & 10.04 & 344.8 & $311.4-375.8$ & $127,361,349-137,839,102$ & n.a. & n.a. \\
\hline
\end{tabular}




\section{Competing interests}

The authors declare that they have no competing interests.

\section{Authors' contributions}

YQH designed the study. TTJ and YQH performed the analyses and drafted the manuscript. JTC, LYZ, YFZ and JJG made acquisition of data. All authors critically revised and provided final approval of this manuscript.

\section{Acknowledgements}

This work was supported by a grant from the Hebei Province Science and Technology Support Program, China (12225510D, 14226305D-5). We thank Jeffery, Simon at Wageningen University for the linguistic modification of this manuscript.

\section{Received: 29 October 2014 Accepted: 29 January 2015}

\section{Published online: 14 February 2015}

\section{References}

1. Broadley MR, White PJ, Hammond JP, Zelko I, Lux A. Zinc in plants. New Phytol. 2007;173:677-702.

2. World Health Organization. The World Health Report 2002: Reducing Risks, Promoting Healthy Life. Geneva: WHO; 2002.

3. Hotz C, Brown $\mathrm{KH}$. Assessment of the risk of zinc deficiency in populations and options for its control. Tokyo: International Nutrition Foundation for UNU; 2004.

4. Boccio J, lyengar $V$. Iron deficiency-causes, consequences, and strategies to overcome this nutritional problem. Biol Trace Elem Res. 2003;94:1-31.

5. Rawat N, Neelam K, Tiwari VK, Dhaliwal HS, Balyan H. Biofortification of cereals to overcome hidden hunger. Plant Breed. 2013;132:437-45.

6. Bouis HE. Micronutrient fortification of plants through plant breeding: can it improve nutrition in man at low cost? Proc Nutr Soci. 2003;62:403-11.

7. Bouis HE, Welch RM. Biofortification-a sustainable agricultural strategy for reducing micronutrient malnutrition in the global south. Crop Sci. 2010:50:520-32.

8. White PJ, Broadley MR. Biofortifying crops with essential mineral elements Trends Plant Sci. 2005;10:586-93.

9. Stangoulis JCR, Huynh B-L, Welch RM, Choi E-Y, Graham RD. Quantitative trait loci for phytate in rice grain and their relationship with grain micronutrient content. Euphytica. 2007;154:289-94.

10. Li M, Wang H, Zhang J, Lee J, Yang R, Zhou Y, et al. QTL mapping and epistasis analysis for phytic acid concentration in rice grain by using the bayesian model selection. Chin J Rice Sci. 2009;23:475-80.

11. Zhang X, Yang L, Zhang T, Jiang K, Wang G, Zheng J, et al. QTL mapping for zinc content in rice grains. Chin Bull Bot. 2009;44:594-600.

12. Du J, Zeng D, Wang B, Qian Q, Zheng S, Ling HQ. Environmental effects on mineral accumulation in rice grains and identification of ecological specific QTLs. Environ Geochem Health. 2012:35:161-70.

13. Huang Y, Zou D, Wang J, Liu H, Xing W, Ma J, et al. QTL mapping for Mn, Fe, Zn and Cu contents in rice grains. Crop. 2012;6:77-81.

14. Sun MM. Genetic Analysis and QTL Mapping of the Contents for Mineral Elements Such as Fe, Se, Zn, Cu and Anthocyanins in Rice Seed, PhD thesis. Shandong Agricultural University: Crop Genetic and Breeding; 2006.

15. Zhong L. QTL Analysis on Mineral Elements Content in Rice, PhD Thesis. Sichuan Agricultural University: Crop Genetics and Breeding; 2010

16. Hu X. Dissection of QTLs for Yield and Grain Quality and Genetic Background Effect on Their Expression Using Backcross Intergression Lines of Rice, PhD Thesis. Chinese Academy of Agricultural Science: Crop Genetic \& Breeding; 2011.

17. Jin T, Zhou J, Chen J, Zhu L, Zhao Y, Huang Y. The genetic architecture of zinc and iron content in maize grains as revealed by QTL mapping and meta-analysis. Breed Sci. 2013;63:317-24.

18. Lung'aho MG, Mwaniki AM, Szalma SJ, Hart JJ, Rutzke MA, Kochian LV, et al. Genetic and physiological analysis of iron biofortification in maize kernels. PLoS One. 2011;6:e20429.

19. Qin H, Cai Y, Liu Z, Wang G, Wang J, Guo Y, et al. Identification of QTL for zinc and iron concentration in maize kernel and cob. Euphytica. 2012;187:345-58

20. Simic D, Mladenovic Drinic S, Zdunic Z, Jambrovic A, Ledencan T, Brkic J, et al. Quantitative trait loci for biofortification traits in maize grain. J Hered. 2012;103:47-54.
21. Goffinet B, Gerber S. Quantitative trait loci: a meta-analysis. Genet. 2000;155:463-73.

22. Li JZ, Zhang ZW, Li YL, Wang QL, Zhou YG. QTL consistency and meta-analysis for grain yield components in three generations in maize. Theor Appl Genet. 2011;122:771-82

23. Swamy BP, Vikram P, Dixit S, Ahmed HU, Kumar A. Meta-analysis of grain yield QTL identified during agricultural drought in grasses showed consensus. BMC Genomics. 2011;12:319.

24. Sun $Y N$, Pan JB, Shi XL, Du XY, Wu Q, Qi ZM, et al. Multi-environment mapping and meta-analysis of 100-seed weight in soybean. Mol Biol Rep. 2012;39:9435-43.

25. Chardon F, Virlon B, Moreau L, Falque M, Joets J, Decousset L, et al. Genetic architecture of flowering time in maize as inferred from quantitative trait loci meta-analysis and synteny conservation with the rice genome. Genet. 2004;168:2169-85.

26. Xu J, Liu Y, Liu J, Cao M, Wang J, Lan H, et al. The genetic architecture of flowering time and photoperiod sensitivity in maize as revealed by QTL review and meta analysis. J Integr Plant Biol. 2012;54:358-73.

27. Hao Z, Li X, Liu X, Xie C, Li M, Zhang D, et al. Meta-analysis of constitutive and adaptive QTL for drought tolerance in maize. Euphytica. 2009;174:165-77.

28. Courtois B, Ahmadi N, Khowaja F, Price AH, Rami J-F, Frouin J, et al. Rice root genetic architecture: meta-analysis from a drought QTL database. Rice. 2009;2:115-28.

29. Khowaja FS, Norton GJ, Courtois B, Price AH. Improved resolution in the position of drought-related QTLs in a single mapping population of rice by meta-analysis. BMC Genomics. 2009;10:276.

30. Löffler M, Schön C-C, Miedaner T. Revealing the genetic architecture of FHB resistance in hexaploid wheat (Triticum aestivum L.) by QTL meta-analysis. Mol Breed. 2009;23:473-88.

31. Rodríguez VM, Butrón A, Rady MOA, Soengas $P$, Revilla P. Identification of quantitative trait loci involved in the response to cold stress in maize (Zea mays L.). Mol Breed. 2013;33:363-71.

32. Liu R, Zhang H, Zhao P, Zhang Z, Liang W, Tian Z, et al. Mining of candidate maize genes for nitrogen use efficiency by integrating gene expression and QTL data. Plant Mol Biol Rep. 2011;30:297-308.

33. Xiang $\mathrm{K}$, Reid LM, Zhang Z-M, Zhu X-Y, Pan G-T. Characterization of correlation between grain moisture and ear rot resistance in maize by QTL meta-analysis. Euphytica. 2011;183:185-95.

34. Sala RG, Andrade FH, Cerono JC. Quantitative trait loci associated with grain moisture at harvest for line per se and testcross performance in maize: a meta-analysis. Euphytica. 2012;185:429-40.

35. Hund A, Reimer R, Messmer R. A consensus map of QTLs controlling the root length of maize. Plant Soil. 2011;344:143-58.

36. Ku LX, Zhang J, Guo SL, Liu HY, Zhao RF, Chen YH. Integrated multiple population analysis of leaf architecture traits in maize (Zea mays L.). J Exp Bot. 2012;63:261-74.

37. Lacape J-M, Llewellyn D, Jacobs J, Arioli T, Becker D, Calhoun S, et al. Meta-analysis of cotton fiber quality QTLs across diverse environments in a Gossypium hirsutum x G. barbadense RIL population. BMC Plant Biol. 2010;10:132.

38. Z-m Q. Soybean oil content QTL mapping and integrating with meta-analysis method for mining genes. Euphytica. 2011;179:499-514.

39. Danan S, Veyrieras J-B, Lefebvre V. Construction of a potato consensus map and QTL meta-analysis offer new insights into the genetic architecture of late blight resistance and plant maturity traits. BMC Plant Biol. 2011;11:16.

40. Ahn S, Tanksley S. Comparative linkage maps of the rice and maize genomes. Proc Natl Acad Sci U S A. 1993;90:7980-4.

41. Gale MD, Devos KM. Comparative genetics in the grasses. Proc Natl Acad Sci U S A. 1998:95:1971-4.

42. Yan J-B, Tang H, Huang Y-Q, Zheng Y-L, Li J-S. Comparative analyses of QTL for important agronomic traits between maize and rice. Acta Genet Sin. 2004;31:1401-7.

43. Wang $Y$, Yao J, Zhang Z, Zheng Y. The comparative analysis based on maize integrated QTL map and meta-analysis of plant height QTLs. Chin Sci Bull. 2006;51:2219-30

44. Zhou X, Li S, Zhao Q, Liu X, Zhang S, Sun C, et al. Genome-wide identification, classification and expression profiling of nicotianamine synthase (NAS) gene family in maize. BMC Genomics. 2013;14:238.

45. Li S, Zhou X, Huang Y, Zhu L, Zhang S, Zhao Y, et al. Identification and characterization of the zinc-regulated transporters, iron-regulated transporter-like protein (ZIP) gene family in maize. BMC Plant Biol. 2013;13:114. 
46. Zheng L, Cheng Z, Ai C, Jiang X, Bei X, Zheng Y, et al. Nicotianamine, a novel enhancer of rice iron bioavailability to humans. PLoS One. 2010;5:e10190

47. Lee S, Kim YS, Jeon US, Kim YK, Schjoerring JK, An G. Activation of Rice nicotianamine synthase 2 (OsNAS2) enhances iron availability for biofortification. Mol Cells. 2012:33:269-75.

48. Lee S, Jeon US, Lee SJ, Kim YK, Persson DP, Husted S, et al. Iron fortification of rice seeds through activation of the nicotianamine synthase gene. Proc Natl Acad Sci U S A. 2009;106:22014-9.

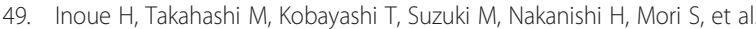
Identification and localisation of the rice nicotianamine aminotransferase gene OsNAAT1 expression suggests the site of phytosiderophore synthesis in rice. Plant Mol Biol. 2008;66:193-203.

50. Cheng L, Wang F, Shou H, Huang F, Zheng L, He F, et al. Mutation in nicotianamine aminotransferase stimulated the $\mathrm{Fe}(\mathrm{II})$ acquisition system and led to iron accumulation in rice. Plant Physiol. 2007;145:1647-57.

51. Bashir $\mathrm{K}$, Inoue $\mathrm{H}$, Nagasaka S, Takahashi M, Nakanishi H, Mori S, et al. Cloning and characterization of deoxymugineic acid synthase genes from graminaceous plants. J Biol Chem. 2006;281:32395-402.

52. Nozoye T, Nagasaka S, Kobayashi T, Takahashi M, Sato Y, Uozumi N, et al. Phytosiderophore efflux transporters are crucial for iron acquisition in graminaceous plants. J Biol Chem. 2011;286:5446-54.

53. Koike S, Inoue H, Mizuno D, Takahashi M, Nakanishi H, Mori S, et al. OsYSL2 is a rice metal-nicotianamine transporter that is regulated by iron and expressed in the phloem. Plant J. 2004;39:415-24.

54. Ishimaru $Y$, Masuda H, Bashir $\mathrm{K}$, Inoue $\mathrm{H}$, Tsukamoto $T$, Takahashi M, et al. Rice metal-nicotianamine transporter, OSYSL2, is required for the long-distance transport of iron and manganese. Plant J. 2010;62:379-90.

55. Sasaki A, Yamaji N, Xia J, Ma JF. OsYSL6 is involved in the detoxification of excess manganese in rice. Plant Physiol. 2011;157:1832-40.

56. Inoue H, Kobayashi T, Nozoye T, Takahashi M, Kakei Y, Suzuki K, et al. Rice OsYSL15 is an iron-regulated iron(III)-deoxymugineic acid transporte expressed in the roots and is essential for iron uptake in early growth of the seedlings. J Biol Chem. 2009;284:3470-9.

57. Lee S, Chiecko JC, Kim SA, Walker EL, Lee Y, Guerinot ML, et al. Disruption of OsYSL15 leads to iron inefficiency in rice plants. Plant Physiol. 2009:150:786-800

58. Kakei Y, Ishimaru Y, Kobayashi T, Yamakawa T, Nakanishi H, Nishizawa NK. OsYSL16 plays a role in the allocation of iron. Plant Mol Biol. 2012;79:583-94.

59. Lee S, Ryoo N, Jeon JS, Guerinot ML, An G. Activation of rice Yellow Stripe1Like 16 (OsYSL16) enhances iron efficiency. Mol Cells. 2012;33:117-26.

60. Aoyama T, Kobayashi T, Takahashi M, Nagasaka S, Usuda K, Kakei Y, et al OsYSL18 is a rice iron(III)-deoxymugineic acid transporter specifically expressed in reproductive organs and phloem of lamina joints. Plant Mol Biol. 2009;70:681-92

61. Bughio N, Yamaguchi H, Nishizawa NK, Nakanishi H, Mori S. Cloning an iron-regulated metal transporter from rice. J Exp Bot. 2002;53:1677-82.

62. Lee S, An G. Over-expression of OsIRT1 leads to increased iron and zinc accumulations in rice. Plant Cell Environ. 2009;32:408-16.

63. Ishimaru Y, Suzuki M, Tsukamoto T, Suzuki K, Nakazono M, Kobayashi T, et al. Rice plants take up iron as an $\mathrm{Fe}^{3+}$-phytosiderophore and as $\mathrm{Fe}^{2+}$. Plant J. 2006;45:335-46.

64. Ramesh SA. Differential metal selectivity and gene expression of two zinc transporters from rice. Plant Physiol. 2003;133:126-34.

65. Ishimaru Y, Suzuki M, Kobayashi T, Takahashi M, Nakanishi H, Mori S, et al. OsZIP4, a novel zinc-regulated zinc transporter in rice. J Exp Bot. 2005:56:3207-14.

66. Ishimaru Y, Masuda H, Suzuki M, Bashir K, Takahashi M, Nakanishi H, et al. Overexpression of the OsZIP4 zinc transporter confers disarrangement of zinc distribution in rice plants. J Exp Bot. 2007:58:2909-15.

67. Lee S, Jeong HJ, Kim SA, Lee J, Guerinot ML, An G. OsZIP5 is a plasma membrane zinc transporter in rice. Plant Mol Biol. 2010;73:507-17.

68. Yang $X$, Huang J, Jiang $Y$, Zhang HS. Cloning and functional identification of two members of the ZIP (Zrt, Irt-like protein) gene family in rice (Oryzo sativa L.). Mol Biol Rep. 2009;36:281-7.

69. Lee S, Kim SA, Lee J, Guerinot ML, An G. Zinc deficiency-inducible OsZIP8 encodes a plasma membrane-localized zinc transporter in rice. Mol Cells. 2010;29:551-8.

70. Takahashi R, Ishimaru Y, Senoura T, Shimo H, Ishikawa S, Arao T, et al. The OsNRAMP1 iron transporter is involved in Cd accumulation in rice. J Exp Bot. 2011;62:4843-50.
71. Xia J, Yamaji N, Kasai T, Ma JF. Plasma membrane-localized transporter for aluminum in rice. Proc Natl Acad Sci U S A. 2010;107:18381-5.

72. Yang $M$, Zhang $W$, Dong $H$, Zhang $Y$, LV K, Wang D, et al. OsNRAMP3 is a vascular bundles-specific manganese transporter that is responsible for manganese distribution in rice. PLoS One. 2013:8:e83990.

73. Ishimaru Y, Takahashi R, Bashir K, Shimo H, Senoura T, Sugimoto K, et al. Characterizing the role of rice NRAMP5 in Manganese, Iron and Cadmium Transport. Sci Rep. 2012:2:286

74. Sasaki A, Yamaji N, Yokosho K, Ma JF. Nramp5 is a major transporter responsible for manganese and cadmium uptake in rice. Plant Cell. 2012;24:2155-67

75. Satoh-Nagasawa N, Mori M, Nakazawa N, Kawamoto T, Nagato Y, Sakurai K, et al. Mutations in rice (Oryza sativa) heavy metal ATPase 2 (OsHMA2) restrict the translocation of zinc and cadmium. Plant Cell Physiol. 2012:53:213-24

76. Takahashi R, Ishimaru Y, Shimo H, Ogo Y, Senoura T, Nishizawa NK, et al. The OsHMA2 transporter is involved in root-to-shoot translocation of $\mathrm{Zn}$ and $\mathrm{Cd}$ in rice. Plant Cell Environ. 2012;35:1948-57

77. Yamaji N, Xia J, Mitani-Ueno N, Yokosho K, Feng Ma J. Preferential delivery of zinc to developing tissues in rice is mediated by P-type heavy metal ATPase OsHMA2. Plant Physiol. 2013;162:927-39.

78. Ueno D, Yamaji N, Kono I, Huang CF, Ando T, Yano M, et al. Gene limiting cadmium accumulation in rice. Proc Natl Acad Sci U S A. 2010;107:16500-5.

79. Miyadate H, Adachi S, Hiraizumi A, Tezuka K, Nakazawa N, Kawamoto T, et al. OsHMA3, a P1B-type of ATPase affects root-to-shoot cadmium translocation in rice by mediating efflux into vacuoles. New Phytol. 2011;189:190-9.

80. Deng F, Yamaji N, Xia J, Ma JF. A member of the heavy metal P-type ATPase OsHMA5 is involved in xylem loading of copper in rice. Plant Physiol. 2013;163:1353-62

81. Lee $S$, Kim $Y Y$, Lee $Y$, An G. Rice P1B-type heavy-metal ATPase, OsHMA9, is a metal efflux protein. Plant Physiol. 2007;145:831-42.

82. Yuan L, Yang S, Liu B, Zhang M, Wu K. Molecular characterization of a rice metal tolerance protein, OsMTP1. Plant Cell Rep. 2012;31:67-79.

83. Menguer PK, Farthing E, Peaston KA, Ricachenevsky FK, Fett JP, Williams LE. Functional analysis of the rice vacuolar zinc transporter OsMTP1. J Exp Bot. 2013;64:2871-83.

84. Chen Z, Fujii Y, Yamaji N, Masuda S, Takemoto Y, Kamiya T, et al. Mn tolerance in rice is mediated by MTP8.1, a member of the cation diffusion facilitator family. J Exp Bot. 2013;64:4375-87.

85. Yokosho K, Yamaji N, Ueno D, Mitani N, Ma JF. OsFRDL1 is a citrate transporter required for efficient translocation of iron in rice. Plant Physiol. 2009;149:297-305.

86. Zhang $Y, X u$ YH, Yi HY, Gong JM. Vacuolar membrane transporters OsVIT1 and OsVIT2 modulate iron translocation between flag leaves and seeds in rice. Plant J. 2012;72:400-10.

87. Bashir K, Takahashi R, Akhtar S, Ishimaru Y, Nakanishi H, Nishizawa NK. The knockdown of OsVIT2 and MIT affects iron localization in rice seed. Rice. 2013;6:1-7.

88. Ogo Y, Itai RN, Nakanishi H, Inoue H, Kobayashi T, Suzuki M, et al. Isolation and characterization of IRO2, a novel iron-regulated bHLH transcription factor in graminaceous plants. J Exp Bot. 2006;57:2867-78.

89. Ogo Y, Itai RN, Nakanishi H, Kobayashi T, Takahashi M, Mori S, et al. The rice bHLH protein OsIRO2 is an essential regulator of the genes involved in Fe uptake under Fe-deficient conditions. Plant J. 2007;51:366-77.

90. Ogo Y, Itai RN, Kobayashi T, Aung MS, Nakanishi H, Nishizawa NK. OsIRO2 is responsible for iron utilization in rice and improves growth and yield in calcareous soil. Plant Mol Biol. 2011;75:593-605.

91. Zheng L, Ying Y, Wang L, Wang F, Whelan J, Shou H. Identification of a novel iron regulated basic helix-loop-helix protein involved in Fe homeostasis in Oryza sativa. BMC Plant Biol. 2010;10:166.

92. Zhang H, Uddin MS, Zou C, Xie C, Xu Y, Li WX. Meta-analysis and candidate gene mining of low-phosphorus tolerance in maize. J Integr Plant Biol. 2014:56:262-70.

93. Truntzler M, Barriere Y, Sawkins MC, Lespinasse D, Betran J, Charcosset A, et al. Meta-analysis of QTL involved in silage quality of maize and comparison with the position of candidate genes. Theor Appl Genet. 2010;121:1465-82

94. Wang $Y$, Huang Z, Deng D, Ding $H$, Zhang R, Wang S, et al. Meta-analysis combined with syntenic metaQTL mining dissects candidate loci for maize yield. Mol Breed. 2013;31:601-14. 
95. Vidal SM, Malo D, Vogan K, Skamene E, Gros P. Natural resistance to infection with intracellular parasites: Isolation of a candidate for Bcg. Cell. 1993;73:469-85.

96. Cellier M, Prive G, Belouchi A, Kwan T, Rodrigues V, Chia W, et al. Nramp defines a family of membrane proteins. Proc Natl Acad Sci U S A. 1995;92:10089-93.

97. CURIE C, Alonso J, LE JEAN M, Ecker J, Briat J. Involvement of NRAMP1 from Arabidopsis thaliana in iron transport. Biochem J. 2000;347:749-55.

98. Ishimaru Y, Bashir K, Nakanishi H, Nishizawa NK. OsNRAMP5, a major player for constitutive iron and manganese uptake in rice. Plant Signal Behav. 2012:7:763-6.

99. Belouchi A, Kwan T, Gros P. Cloning and characterization of the OsNramp family from Oryza sativa, a new family of membrane proteins possibly implicated in the transport of metal ions. Plant Mol Biol. 1997;33:1085-92.

100. Narayanan NN, Vasconcelos MW, Grusak MA. Expression profiling of Oryza sativa metal homeostasis genes in different rice cultivars using a cDNA macroarray. Plant Physiol Biochem. 2007:45:277-86.

101. Thomine S, Wang R, Ward JM, Crawford NM, Schroeder JI. Cadmium and iron transport by members of a plant metal transporter family in Arabidopsis with homology to Nramp genes. Proc Natl Acad Sci U S A. 2000;97:4991-6.

102. Lanquar V, Ramos MS, Lelièvre F, Barbier-Brygoo H, Krieger-Liszkay A, Krämer $U$, et al. Export of vacuolar manganese by AtNRAMP3 and AtNRAMP4 is required for optimal photosynthesis and growth under manganese deficiency. Plant Physiol. 2010;152:1986-99.

103. Thomine S, Lelièvre F, Debarbieux E, Schroeder Jl, Barbier-Brygoo H. AtNRAMP3, a multispecific vacuolar metal transporter involved in plant responses to iron deficiency. Plant J. 2003;34:685-95.

104. Temnykh S, DeClerck G, Lukashova A, Lipovich L, Cartinhour S, McCouch S. Computational and experimental analysis of microsatellites in rice (Oryza sativa L.): frequency, length variation, transposon associations, and genetic marker potential. Genome Res. 2001;11:1441-52.

105. Arcade A, Labourdette A, Falque M, Mangin B, Chardon F, Charcosset A, et al. BioMercator: integrating genetic maps and QTL towards discovery of candidate genes. Bioinformatics. 2004;20:2324-6.

106. Larkin MA, Blackshields G, Brown N, Chenna R, McGettigan PA, McWilliam H, et al. Clustal W and Clustal X version 2.0. Bioinformatics. 2007;23:2947-8.

107. Tamura K, Dudley J, Nei M, Kumar S. MEGA4: molecular evolutionary genetics analysis (MEGA) software version 4.0. Mol Biol Evol. 2007;24:1596-9.

\section{Submit your next manuscript to BioMed Central and take full advantage of:}

- Convenient online submission

- Thorough peer review

- No space constraints or color figure charges

- Immediate publication on acceptance

- Inclusion in PubMed, CAS, Scopus and Google Scholar

- Research which is freely available for redistribution 